\title{
An exploration of the choices of patients with chronic kidney disease
}

\author{
This article was published in the following Dove Press journal: \\ Patient Preference and Adherence \\ 24 October 2014 \\ Number of times this article has been viewed
}

\author{
Sinead Keeney' \\ Hugh McKenna ${ }^{2}$ \\ 'Institute of Nursing Research, \\ University of Ulster, ${ }^{2}$ Research and \\ Innovation, University of Ulster, \\ Newtownabbey, Northern Ireland
}

Correspondence: Sinead Keeney Institute of Nursing Research, University of Ulster, Shore Road, Newtownabbey, Co. Antrim BT37 0QB, Northern Ireland Email sr.keeney@ulster.ac.uk
Background: Chronic kidney disease (CKD) is a progressive loss of renal function over a period of time. It is common, often unrecognized, and frequently coexists with other conditions, including diabetes and cardiovascular disease. There has been little research undertaken into treatment options and decision-making processes of CKD patients in general.

Objectives: To determine the treatment options that CKD patients are offered and their views and experiences with regard to these choices.

Design: A survey design was adopted.

Participants: Participants included patients who had CKD at the time of the study and who were on renal dialysis.

Results: A wide range of findings emerged from the study. Key findings showed that the majority of patients felt that written information was the main source of information, but that almost one-quarter of patients felt that they did not receive enough information about dialysis to allow them to make an informed choice. Almost one-fifth of participants did not consider that they had been strongly encouraged by health professionals to be independent with regard to their choice of dialysis.

Conclusion: While the majority of patients feel fully informed and involved in the decisionmaking processes around treatment and management of their CKD, not all patients receive sufficient information to make an informed choice about their treatment and that treatment options are not always presented to patients and their families to enable them to make a fully informed choice.

Keywords: choice, patient, treatment, information

\section{Introduction}

Over the past 2 decades, the availability of health information has expanded rapidly. ${ }^{1}$ Patients are now likely to be active participants and decision-makers in their own health care. ${ }^{2,3}$ This is a departure from the traditional "paternalistic" model of doctor-led health care, wherein medical staff made the decisions and patients had little input. ${ }^{4-6}$ Policymakers worldwide are now increasingly viewing health as the individual's responsibility, ${ }^{7}$ and the promotion of patient involvement is strongly advocated in the prevention and management of chronic conditions. ${ }^{6}$ Furthermore, policymakers believe that encouraging patients to play a more active role in their own health care could improve quality, efficiency, and outcomes. ${ }^{8}$ Patient-centered care based on doctors responding to patients' preferences for care and treatment includes the patient involvement in decision-making. ${ }^{4}$ There is a growing body of literature exploring patients' involvement in decision-making about treatment. ${ }^{9-11}$

The aim of this study was to determine what choices patients with chronic kidney disease (CKD) are currently offered in Northern Ireland and their views and experiences with regard to these choices. 


\section{Background}

CKD is a progressive loss of renal function over a period of time. It is common, often unrecognized, and frequently coexists with other conditions, including diabetes and cardiovascular disease. ${ }^{12}$ It is considered to be the reduction of the functioning of the kidneys to filter blood (European Kidney Patients' Federation 2012). CKD has emerged as a significant public health problem, with estimates of up to $10 \%$ of the adult population having evidence of CKD or risk factors for the disease. The number of patients developing the need for renal replacement treatment continues to grow and is expected to increase over the next decade. ${ }^{13}$ The main difficulty with the treatment and management of CKD is the sizable burden that it places on health care resources coupled with the need that patients have for specialist services. Although there is evidence that large numbers of CKD patients exist worldwide, there is limited evidence available on the influencing factors in choice of treatment from the patient's perspective. ${ }^{14,15}$ Indeed, it is also apparent that there has been little research undertaken into the choices of CKD patients in general. ${ }^{16,17}$

Progression of CKD to an advanced stage can potentially lead to end-stage kidney disease with a requirement for renal replacement therapy. The provision of information in terms of choice of different renal replacement therapy modalities is the subject of this paper.

\section{Literature}

There is a wealth of existing literature around patients' modality choices for treatment of CKD..$^{2,13,15,17-24}$ However, there is a limited amount of evidence from the patient's point of view with regard to factors influencing their choice of treatment. ${ }^{11}$

Several systematic reviews have been undertaken in this area. ${ }^{11,14}$ Murray et al' $\mathrm{s}^{11}$ review explored the factors influencing patient involvement in decision-making in relation to CKD. No studies were uncovered that identified the patient's point of view regarding influencing factors on treatment decision-making. Review findings showed that factors influencing CKD patients' involvement in decision-making included: interpersonal relationships; preserving current wellbeing, normality, and quality of life; need for control; and personal importance placed on benefits and risks. ${ }^{11}$

Morton et al's ${ }^{14}$ systematic review explored the literature around the views of patients and carers in decision-making about treatment for CKD and the factors influencing these decisions. Findings showed that four main themes emerged across the studies: confronting mortality; lack of choice; gaining knowledge of options; and weighing alternatives. The experience of other patients was a significant influence in the decision-making of patients and carers, as were family/carer influences. Additionally, there was a preference to "maintain the status quo", ${ }^{14}$ which the authors concluded may explain why patients often remain on their initial treatment modality. Lack of choice due to coexisting conditions or due to the health professional's preference for a certain treatment were both highlighted as important factors in patient choice. Lack of information was also considered to limit patient choice, as patients sometimes felt that they were not in possession of all the information about treatment.

Harwood and Clark's ${ }^{24}$ meta-synthesis of qualitative studies examined how patients with CKD make decisions about treatment and which factors influenced the decisions. Findings showed that factors influencing choices were: the illusion of choice (matters of life and death); minimizing the impact of dialysis on life (control, values, sense of self); and decision-making in the context of knowledge and support. The authors concluded from the review that decisions about treatment are strongly influenced by patient and family values, the patient's own personal circumstances, and the least disruption to their quality of life possible. Similar to a study undertaken by Lee et al, ${ }^{23}$ Harwood and Clark ${ }^{24}$ stated that there is a need for planned and timely discussion about treatment in which home dialysis is presented as a viable option for patients and that there is a greater focus on patients' own circumstances and preferences.

Findings from Little et al's $\mathrm{s}^{21}$ study, undertaken in England, showed that, of the 254 patients in the study with a free choice as to what type of dialysis they wanted, 139 patients (55\%) chose hemodialysis (HD) and 115 patients (45\%) chose continuous ambulatory peritoneal dialysis (CAPD). Factors influencing the choice of CAPD included being married, receiving counseling before making a choice, and living further away from the dialysis center. Predictors of choosing HD included being older and being male. Similarly, Szabo et al's ${ }^{18}$ findings showed that patients in the "no-choice" group had a lower quality of life score than the patients who had a choice about the type of dialysis to have. The authors concluded that, once the choice or treatment is removed from the patient, their psychological quality of life deteriorates.

Many of the studies undertaken in this area have examined the effect of demographic and social factors as influences on choice of treatment. ${ }^{2,15,20,22,26,27}$

Wuerth et al's ${ }^{20}$ USA study showed that all chronic peritoneal dialysis (CPD) patients in the study stated that they chose their own treatment, but only eight of the $20 \mathrm{HD}$ patients reported that they chose their treatment. Overall, $83 \%$ of patients stated that their consultant was their primary 
influencing factor in their choice of treatment. CPD patients were more likely to rely on written information and their family and friends as influences in their decisions about treatment. Overall, $95 \%$ of patients felt that control and autonomy were important for them with regard to their treatment.

Orsino et $\mathrm{al}^{2}$ reported similar findings in their Canadian study, in which the findings showed that $23.9 \%$ of the sample preferred the health care team to make the decision about treatment for them; $41.5 \%$ wanted shared decision-making between themselves and the health care team; and 34.6\% wanted to make their own decision about treatment. However, only $40 \%$ of those who stated that they wanted to make their own decision and $30 \%$ of those who stated that they wanted shared decision-making reported that this was their actual experience. Orsino et al concluded that health care teams should ensure that they find out and meet the information needs of patients and consider the treatment decision-making roles preferred by each patient.

Stack's ${ }^{22}$ American study concluded that there are several clinical, social, and pre-end-stage renal disease factors associated with choice of treatment and highlighted the importance of patient education, autonomy, and a strong support system in improving the rates of peritoneal dialysis (PD) in USA. Morton et al's ${ }^{26}$ study concluded that CKD patients were informed of their treatment options before starting treatment. They suggested that earlier intervention in the form of education and support for making informed decisions would help increase home dialysis therapies. Morton et al's ${ }^{27}$ later study also concluded that home-based dialysis therapy would allow patients and families to travel with little restriction and would be preferred by CKD patients.

Chanouzas et al's ${ }^{15}$ UK study findings showed an association between age and treatment choice. The extent of comorbidity was also associated with treatment choice. Factors considered important by patients in choosing treatment included ability to cope, fitting treatment in with lifestyle, distance to center, and provision of information about treatment. The authors concluded that the provision of good information and pre-dialysis education are crucial in empowering patients to choose self-care therapies. They also asserted that having strong social support and being functionally able to choose PD emphasizes the need for assisted PD.

In 2011, the European Kidney Patients' Federation (CEAPIR) undertook a Europe-wide survey of how patients with CKD perceive information about, access to, and choice of treatment $(n=3,867) .{ }^{17}$ Findings showed that one-quarter of respondents did not remember receiving information about reduced kidney function before they started dialysis. Almost two-thirds stated that they felt that they did not receive the education or information needed to help them deal with their condition in relation to their everyday life. Over $40 \%$ identified doctors and nurses as their main sources of information. In relation to patient involvement, the survey showed that $75 \%$ of respondents felt involved in decisions about treatment, but $25 \%$ did not feel involved. Further findings revealed that over $50 \%$ of respondents stated that they could choose their own treatment. ${ }^{17}$ Findings from the UK showed that $50 \%$ of UK respondents felt very involved in decision-making about their treatment. This is reported to be consistent with the European averages, but is a lower level of reported involvement than in Belgium or Hungary. ${ }^{17}$

Several qualitative studies have also been undertaken in this area to try to gain further insight into the reasons behind patient choices about treatment. ${ }^{13,19,23,28}$ Findings from Tweed and Ceaser's ${ }^{13}$ UK study showed that four main themes emerged from the data relating to decision-making: maintaining integrity, forced adaptation, using information, and support. The authors concluded that there is a need to tailor information provided to pre-dialysis patients. Breckenridge's ${ }^{19}$ findings showed that the themes emerging from their data reflected two different patterns of decision-making. The first of these was that the treatment was chosen due to clinical or practical circumstances and the second was that the patient or their family chose the treatment themselves. Whittaker and Albee' ${ }^{28}$ findings also showed that there were two stages involved in patients making a decision about treatment. The first stage was concerned with "valuing and evaluating perceived threats". ${ }^{28}$ The second stage was about considering the alternatives to the preferred treatment, comparing the benefits and disadvantages of each treatment modality, and, finally, choosing the treatment that produces the least perceived "threats" and provides the most support for "values". ${ }^{28}$

Lee et al' ${ }^{23}$ Danish study findings showed that flexibility, independence, and feeling secure were key factors in the choice of treatment. Similarly to Breckenridge's ${ }^{19}$ findings, maintenance of normal life was viewed by the patients as a major goal. Patients and relatives wanted to participate in the choice of treatment. With regard to "out-of-center" dialysis, Lee et $\mathrm{al}^{23}$ concluded that this treatment choice needs to have a greater focus on patients' own preferences and their lifestyles as well as a greater focus on pre-dialysis patients.

\section{Methods}

The study was undertaken using a quantitative research design. A questionnaire was developed by the research team to include questions designed by experts in the field of CKD including nurses and nephrologists. Patients were also given an opportunity to comment on the questionnaire. 


\section{Questionnaire design}

The questionnaire included:

- A demographics section;

- A section on treatment asking patients about type of treatment, where treatment is received, length of time spent traveling to treatment, and frequency;

- A section relating to communications about CKD and treatment, including who discussed diagnosis and treatment with the patient, length of time spent at and frequency of appointments with consultant and pre-dialysis nurse, and information provision regarding $\mathrm{CKD}$, treatment and lifestyle;

- Questions on involvement in decision-making regarding treatment;

- Questions about influencing factors regarding decisions about treatment; and

- A section about patients' understanding of the different types of treatment.

In total, there were 28 questions, the majority of which were closed questions requiring only a tick-box response. Two questions at the end of the questionnaire were openended and focused on influencing factors about choice of treatment, and a final question allowed the respondent an opportunity to add anything they wished about their experience of choosing their treatment.

Consultation was undertaken with a panel of experts including nurses, and nephrologists to improve the content validity of the survey tool. Minor changes were incorporated into the survey tool at this stage.

\section{Pilot study}

A pilot study was undertaken with a small convenience sample of six patients with CKD currently on renal dialysis. These patients were recruited through a large patients' association. The pilot study survey was administered by telephone. Questions were asked by the researcher, responses outlined, and then the participant's response recorded by the researcher on the questionnaire. The purpose of the pilot study was to determine if the questionnaire worked well in the field and if it was understandable to the participants. Data collected during the pilot study were analyzed, and minor amendments were made to the questionnaire.

\section{Ethical approval}

Ethical approval was granted by an appropriate University Ethics Committee.

\section{Access and recruitment}

The patients' association assisted with recruitment to the main study. The association has access to over 450 people who either have $\mathrm{CKD}$, care for someone with $\mathrm{CKD}$, or have an interest in the area. Information letters about the study and a stamped addressed envelope were included initially with the patients' association newsletter. Patients currently on dialysis who were interested in the study were asked to return their contact details to the research team in a stamped addressed envelope. Information packs including covering letters, participant information sheets, and consent forms were then sent out. Within the information pack, potential participants had the opportunity to read about the study and to make an informed decision about whether they wished to participate. Those who decided to participate were instructed to complete the consent form, including their contact details, and return it to the research team in the provided stamped addressed envelope.

\section{Data collection}

Data collection for this study proved to be very difficult. As consent forms were returned, the researcher made an initial telephone call to the participant to answer any outstanding questions and to set up a convenient time and date for the telephone survey to take place. The researcher then undertook the telephone survey with the participant on that date. Responses to the questions were recorded by the researcher directly onto the survey tool as in the pilot study.

It was intended that the method of administration for the study would continue to be by telephone survey. However, after 40 participants had completed the survey by telephone, no further consent forms were received. An advertisement for the study was placed in the next edition of the patients' association newsletter asking for participants to come forward, but, unfortunately, this yielded no further participants. After much consideration, the research team decided to send a postal questionnaire with an information sheet and stamped addressed envelope to all mailing list contacts through the patients' association. From this approach, a further $86 \mathrm{com}-$ pleted questionnaires were returned. In total, this accounted for 126 completed questionnaires, which yielded a significant amount of data.

\section{Data analysis}

Data from completed questionnaires were input into the Statistical Package for the Social Sciences ([SPSS] v 18). 
Descriptive statistics were generated including mean scores and frequencies. Open-ended questions were content-analyzed for themes using Miles and Huberman' ${ }^{29}$ framework.

\section{Results}

\section{Demographics}

The average age of participants was 69 years and ages ranged from 23 years to 90 years. The average length of time since diagnosis of CKD was 13.6 years, with 55 years being the longest time since diagnosis. The shortest length of time since diagnosis was 1 year.

\section{Type of treatment}

Participants were asked to indicate what type of dialysis they were receiving. Overall, $21 \%$ stated that they were receiving PD and 79\% stated that they were receiving HD. Of those receiving $\mathrm{PD}, 34.6 \%$ were receiving $\mathrm{CAPD}$ and $65.4 \%$ were receiving assisted $\mathrm{PD}$.

\section{Length of time on dialysis}

The average length of time on dialysis among this sample was 8 years. The length of time on dialysis ranged from just commencing ( 0 years) to 35 years. Overall, $87.4 \%$ of participants received treatment at their preferred site, whether that was at home $(26.3 \%)$ or a hospital $(61.1 \%)$. The majority of participants who received treatment at a hospital expressed a preference for having their treatment there (93.5\%). Eighty percent of participants who had similar treatment at home stated that this was their preferred location.

\section{Travel time}

Overall, $44.6 \%$ of participants stated that they spent between 30 and 60 minutes traveling to dialysis. Over 36\% (36.1\%) spent less than 30 minutes traveling. A smaller percentage $(16.9 \%)$ spent between 1 and 2 hours traveling to dialysis, and $2.4 \%$ spent over 2 hours. Participants were asked to indicate their means of travel to dialysis. Figure 1 shows the time spent traveling to dialysis. The majority of participants traveled by car $(66.3 \%)$, over one-fifth $(21.7 \%)$ traveled by taxi, and smaller percentages traveled by train $(2.4 \%)$ and bus (3.6\%). The "other" category included lifts with other people (family or friends), but with means of travel not explicitly stated.

\section{Frequency of dialysis}

Participants were asked to indicate how many times a week they had dialysis. The majority of this sample $(83 \%)$ had dialysis three times per week.

\section{Discussion about dialysis}

Participants were asked to identify who had discussed dialysis with them initially after they were diagnosed with CKD. Figure 2 shows the breakdown of responses to this question. It is clear that most of the sample (78.2\%) identified the consultant as the person who discussed dialysis with them initially. The "other" category mostly included "health professional" but was not specific.

Participants were also asked if they could remember how long their clinic appointment was when they made the decision regarding the type of dialysis that they were going to

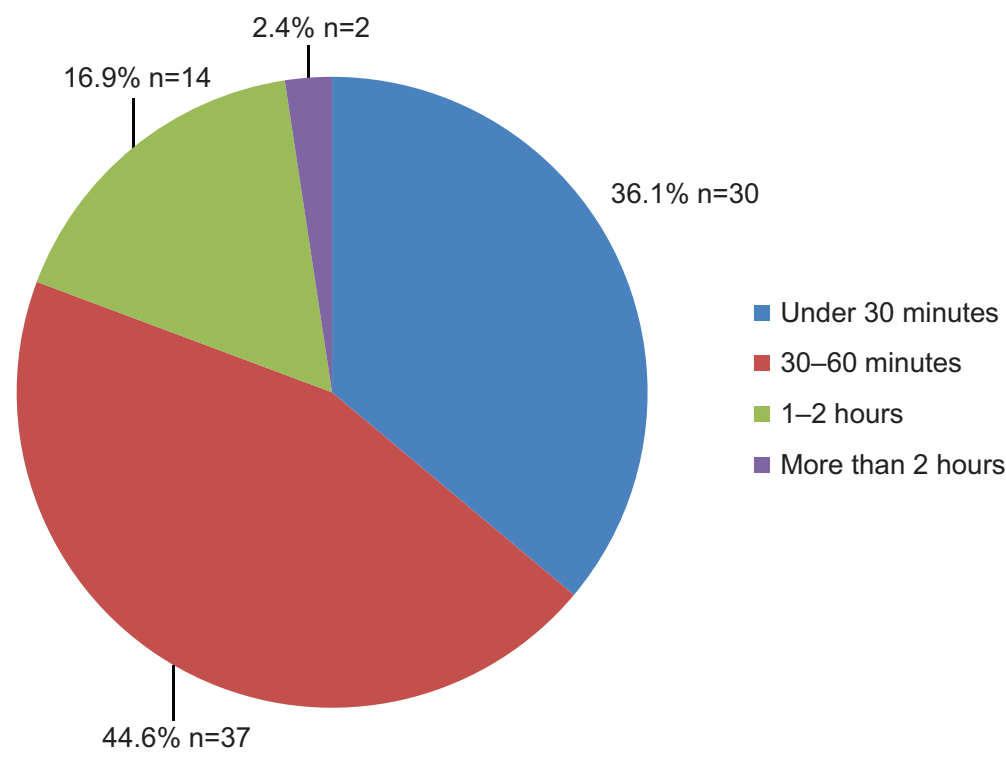

Figure I Patient travel times to dialysis. 


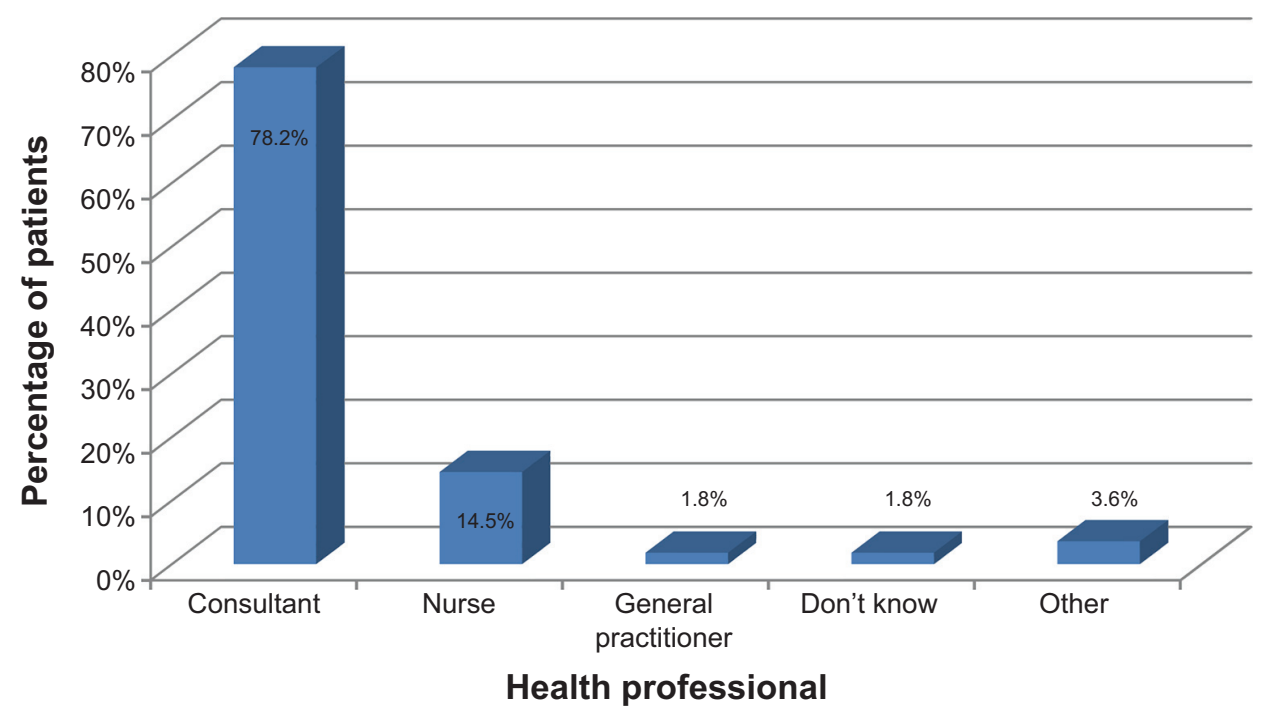

Figure 2 Patient responses regarding with whom they had initially discussed dialysis after diagnosis with chronic kidney disease.

have. Thirty percent of the sample felt that the appointment was between 20 and 30 minutes, while $25 \%$ felt that it was more than 30 minutes. Overall, $25 \%$ stated that they did not remember. This should be taken into consideration when interpreting these results.

Participants were also asked to identify if they were satisfied with the allocated time at the appointment. Overall, $75.2 \%$ of participants were satisfied, $10.4 \%$ of participants were not satisfied, $13.3 \%$ did not remember, and $1.9 \%$ did not know. Participants were also asked to recall who this appointment was with. Most participants felt that this was with the consultant (77.7\%). Almost 4\% did not know, and the "other" category was mostly "health professional" responses, but were not specific.

\section{Pre-dialysis nurse}

Participants were asked if they saw the pre-dialysis nurse before starting dialysis. Overall, $74.3 \%$ of participants stated that they had seen the pre-dialysis nurse prior to commencing dialysis. One-quarter (25.7\%) of the sample stated that they did not see or could not remember seeing the pre-dialysis nurse. Participants were also asked to indicate how often they saw the pre-dialysis nurse before commencing dialysis. Eighteen-and-a-half percent of the participants reported that this was on a weekly basis. It should be noted that $13.6 \%$ stated that they did not know and $21 \%$ of the sample stated "other" but in most instances did not specify exactly how often. Only a small percentage (7.3\%) of participants did not feel that they were allocated enough time with the pre-dialysis nurse compared to $81.7 \%$ who agreed that they did get enough time. Overall, $60.7 \%$ of the sample stated that they were shown the renal dialysis unit and $76.5 \%$ of participants stated that they were shown the dialysis technique.

\section{Information}

Participants were asked about what other sources of information they received when deciding on the type of dialysis that they would have. Almost $70 \%$ of the sample (69.8\%) stated that written information was their primary source, and $90 \%$ of participants stated that this was their secondary source after health professionals. Around 1\% (0.9\%) stated that video information was a key source of information for them, and $6.6 \%$ mentioned that information from other patients was an important source of knowledge for them. Overall, $8.5 \%$ of participants stated "other", and this category included "friends", "internet", and "support groups".

Participants were asked if they felt that they had received enough information about dialysis options to allow them to make an informed choice about what would best suit their lifestyle. Overall, $75.5 \%$ of participants felt that they had received enough to allow them to make an informed choice, with less than one-quarter (24.5\%) feeling that they had not received enough information.

Participants were also asked if they felt that the advantages and disadvantages of the different types of dialysis available were discussed with them. Overall, $72.6 \%$ of the sample indicated that they felt this was discussed and $27.4 \%$ of participants indicated that it was not.

With regard to information about the management and treatment of their CKD, $65.7 \%$ of the sample indicated that they considered the consultant as the main source of information, followed by the nurse (27.8\%). Nurses were considered to be the second key source of information by $72 \%$ of participants. 
Table I Patient responses regarding provision of information

\begin{tabular}{llll}
\hline $\begin{array}{l}\text { Do you think there is enough } \\
\text { information available on }\end{array}$ & $\begin{array}{l}\text { Yes } \\
\text { (\%) }\end{array}$ & $\begin{array}{l}\text { No } \\
\text { (\%) }\end{array}$ & $\begin{array}{l}\text { Don't } \\
\text { know (\%) }\end{array}$ \\
\hline Chronic kidney disease & 64.4 & 24.0 & 11.6 \\
Lifestyle & 64.5 & 27.1 & 8.4 \\
Renal dialysis & 71.6 & 22.0 & 6.4 \\
\hline
\end{tabular}

Participants were asked if they felt that there was enough information available on the key areas of CKD, lifestyle, and renal dialysis. Table 1 shows the results for this question. Around one-quarter of the sample felt that there could be more information available in each of these key areas, and smaller percentages stated that they did not know. For CKD, 24\% felt that more information needed to be available, $27.1 \%$ felt that there needed to be more information on lifestyle, and $22 \%$ felt that there should be more information available on renal dialysis.

\section{Understanding of dialysis}

Participants were asked to indicate their level of understanding of the following: CAPD; assisted PD/automated PD; incenter HD; self-care HD; and home HD. Table 2 shows the level of understanding in each case. It is clear that the highest percentages for each type of dialysis lie in the statement "I was given a full description and fully understand the therapy".

\section{Involvement in decision-making}

Participants were asked to indicate if they felt that they were fully involved in making decisions about their dialysis. Overall, $71.4 \%$ of participants felt that they were fully involved in decision-making about treatment, with $21.9 \%$ stating that they did not feel fully involved. A small percentage (6.7\%) stated they did not know. A further $6.3 \%$ did not answer the question.

Participants were asked to identify their view regarding how well informed they were about CKD and its treatment.
The majority of participants $(65.1 \%)$ felt that their health care professional ensured that they were fully informed about all treatments. Over 14\% felt that they were well informed, but did not feel that they participated in decision-making. Almost $4 \%$ did not feel well informed and did not feel they were able to participate in decision-making. Over $13 \%$ of participants stated that they were not interested in making decisions about their treatment and were happy to leave these decisions with the health care professionals. A small percentage (3.6\%) stated that they did not know, and 5.4\% did not respond to the question. There is an anomaly between the data here, with $21.9 \%$ stating that they did not feel fully involved and subsequently $31 \%$ stating that they felt they did not fully participate in the decision-making process. It may be that participants had different understandings of the terms "fully involved" and "fully informed" within the questionnaire.

\section{Factors influencing decision-making}

The majority of participants $(62.6 \%)$ did not know anyone having dialysis at the time of their decision. Of those participants who did know someone, $68.3 \%$ shared their experiences with each other and $58.8 \%$ felt that this shared experience helped them with arriving at a decision about the type of dialysis to choose. The main themes to emerge from the qualitative comments were understanding of the condition and the choice made from provided information and knowledge. Knowing another person with the condition allowed the participants to have a better understanding of the condition, the types of dialysis, and the pros and cons of each of the techniques involved in dialysis. This better understanding may help to reduce fears and worries associated with the condition.

Over $60 \%$ of participants $(60.7 \%)$ felt that they were encouraged to be independent about their choice of treatment. Almost $20 \%$ of the sample (19.6\%) did not feel that they were encouraged by health professionals to be independent

Table 2 Participants' levels of understanding of dialysis

\begin{tabular}{|c|c|c|c|c|c|}
\hline Statement & CAPD (\%) & APD (\%) & IH (\%) & SCH (\%) & HH (\%) \\
\hline $\begin{array}{l}\text { It was never discussed with me } \\
\text { or my family }\end{array}$ & 12.6 & 16.8 & 7.5 & 28 & 18.4 \\
\hline $\begin{array}{l}\text { It was discussed but I was unable } \\
\text { to get a clear understanding of it }\end{array}$ & 10.7 & 11.6 & 14.2 & 8 & 11.7 \\
\hline $\begin{array}{l}\text { I was given a full description and I } \\
\text { understood the therapy but was told } \\
\text { it was not the best choice for me }\end{array}$ & 28.2 & 23.2 & 8.5 & 15 & 17.5 \\
\hline $\begin{array}{l}\text { I was given a full description and fully } \\
\text { understand the therapy }\end{array}$ & 42.7 & 42.1 & 67 & 42 & 47.6 \\
\hline Don't know/none of the statements & 5.8 & 6.3 & 2.8 & 7 & 4.9 \\
\hline
\end{tabular}

Abbreviations: APD, assisted peritoneal dialysis/automated peritoneal dialysis; CAPD, continuous ambulatory peritoneal dialysis; $\mathrm{HH}$, home hemodialysis; IH, in-center hemodialysis; $\mathrm{SCH}$, self-care hemodialysis. 
about their choice of dialysis. Over $10 \%$ of the sample stated that they did not know, and the remainder did not answer the question. Overall, $43.8 \%$ of participants felt that their family and/or carers were actively involved in the choice of treatment. Among these, $78.6 \%$ found that the involvement of family and/or carers helped to make their decision about the type of dialysis easier.

\section{Influencing factors when choosing treatment}

Participants were asked if there was one single influencing factor that led to their choice of treatment. Over $60 \%$ $(61.4 \%)$ of participants stated that there was. This section of the sample was asked to elaborate on this influencing factor. Three themes emerged from the comments:

- Remaining independent;

- Being able to cope with the demands of the chosen treatment; and

- Being able to manage their treatment.

Participants were asked what factors they felt could have influenced them to be more independent about their choice of dialysis. Two main responses emerged from this question:

- Having more time to make the decision; and

- Having more information.

Participants referred to making an informed choice and being provided with relevant information at the appropriate time by the consultant and nursing staff. The nature of the condition meant that some participants felt that they did not have an opportunity to explore all the relevant information, process it, and ask follow-up questions. It also restricted the amount of time the person had to make a choice regarding type of treatment.

\section{Discussion}

The findings from this survey are wide ranging and cover many key areas, including background and contextual information. Other key areas include diagnosis and treatment, information, understanding of dialysis, decision-making, and factors influencing the choice of dialysis.

Existing literature states that there has been little research to date on decision-making and influencing factors from the patient's perspective. ${ }^{14,15}$ Furthermore, it is clear that there is still limited evidence about the choices of CKD patients in general. ${ }^{16,17}$

Findings from the present study indicate that the consultant is considered the primary source of information about treatment, followed by the nurse. This finding reflects the findings of Wuerth et al's ${ }^{20}$ American study, Lee et al's ${ }^{23}$ Danish study, and Tweed and Ceaser's ${ }^{13}$ UK study. Furthermore, these findings are also reflective of Europe-wide findings, ${ }^{17}$ which stated that doctors and nurses were the main sources of information about treatment. Tweed and Ceaser ${ }^{13}$ concluded that there is a need to tailor information to pre-dialysis patients. Several other studies are also in agreement with these findings and conclude that pre-dialysis patients need to be provided with information tailored to their own preferences and needs. ${ }^{2,15,23}$

Independence emerged as an important influencing factor in choice of treatment in the present study. This also reflects the findings of Wuerth et al's ${ }^{20}$ study in America and Lee et al's ${ }^{23}$ Danish study. Murray et al's ${ }^{11}$ systematic review findings also showed that independence and need for control were important for the patient with regard to choosing treatment.

Results from the European CEAPIR ${ }^{17}$ study showed that $25 \%$ of respondents did not remember receiving information about reduced kidney function before commencing dialysis and almost two-thirds (66\%) felt that they did not receive the information needed to help them deal with their condition in everyday life. In the present study, undertaken in Northern Ireland, 75.5\% stated that they felt they did receive enough information to make an informed choice about which type of dialysis would best suit their lifestyle. This is a much higher figure than the European or UK/Ireland figures.

However, one-quarter of the participants in the present study stated that there was not enough information on lifestyle and $24 \%$ stated that there was not enough information on CKD. This reflects the findings of Morton et al's ${ }^{14}$ study, in which lack of information was sometimes felt to limit patient choice if the patient was not in possession of all the information about treatment.

Patient involvement in decision-making and making informed choices about dialysis and treatment are extremely important issues in this context. Lee et al's ${ }^{23}$ study findings showed that patients wanted to participate in choosing their treatment. The findings from the present study also reflected this, with only $13 \%$ of participants stating that they were not interested in making their own decisions about treatment and were happy to leave these to health professionals. Similarly, findings from Orsino et al's ${ }^{2}$ study showed that less than one-quarter $(23.9 \%)$ of participants wanted the health care team to make the decision for them. In the present study, $70.4 \%$ of participants felt that they were fully involved in the decision-making process, but $21.9 \%$ of participants stated that they did not feel fully involved. This reflects the findings of the European CEAPIR 2012 study, in which one in four respondents $(25 \%)$ stated that they did not feel involved in making the decision about their treatment. When 
the European figures are broken down to country level, the UK data shows that two in ten respondents $(20 \%)$ did not feel involved in the decision-making process. In Ireland, one in five $(20 \%)$ also stated that they did not feel involved in choosing their treatment. Again, this is reflective of the findings from the present study.

Szabo et al's ${ }^{18}$ study stated that, when patients do not have a choice about their type of treatment, their psychological quality of life deteriorates. This demonstrates how important involvement in the decision-making process is when choosing treatment. Furthermore, the willingness and need that participants in these studies display with regard to being involved in decision making adds weight to the shift from the paternalistic model of health care to the shared model. ${ }^{30-32}$

Findings from this study show that almost two-thirds of the sample $(66.7 \%)$ felt that they were encouraged by health professionals to be independent with regard to their choice of dialysis. Overall, $43.8 \%$ of participants felt that their family and/or carers were actively involved in their choice of treatment. Of these, $78.6 \%$ found that the involvement of family and/or carers helped to make their decision about the type of dialysis easier. Participants who knew someone else on dialysis (33.4\%) at the time they were making decisions about treatment felt that the shared experience helped them to arrive at a decision themselves. Morton et al's ${ }^{14}$ findings reflect this, stating that the experience of other patients was a significant influence in the decision-making process for patients.

Influencing factors about choosing treatment uncovered within this study were: remaining independent, being able to manage the uncertainty of the situation, and coping with the demands of the situation. This reflects findings uncovered in the literature. Murray et $\mathrm{al}^{11}$ concluded that preserving current well-being, normality, and quality of life were important influencing factors when choosing treatment. Lee et al's ${ }^{23}$ study undertaken in Denmark also found that maintaining normal life was seen by patients as very important. Furthermore, findings from Chanouzas et al's ${ }^{15}$ UK study showed that participants felt that influencing factors in choosing treatment were the ability to cope and treatment fitting in with current lifestyle, which is similar to the findings from the current study in relation to coping with the demands of the situation and remaining independent. Breckenridge' $\mathrm{s}^{19}$ study and Harwood and Clark's ${ }^{24}$ meta-synthesis of qualitative studies also found that a major influencing factor on choice of treatment was minimizing the impact of dialysis on their life.

\section{Study limitations}

Despite repeated and sustained efforts to recruit people with CKD to the study, it is acknowledged that the response rate to the survey was low. In general, this is a limitation of these types of surveys. It is acknowledged that a large proportion of patients approached did not show interest in the study, which may lead to certain biases. As such, this may not constitute a representative sample of CKD patients in Northern Ireland and this should be considered when interpreting the findings of the study. Furthermore, the change of method from telephone administration of the survey to postal survey was not ideal. In hindsight, data collection with this type of sample may have been more successful within a renal unit while patients were there. It is also acknowledged that some factors that affect decision-making, such as education, economy, ethnicity, comorbidity, were not included in the data collection or analysis within this study. A further limitation of the study is the probable recall bias as a result of patients being asked what information they received about their treatment options after being on dialysis for up to 35 years (mean 8 years).

\section{Conclusion}

This study aimed to understand what choices patients with CKD are currently offered in Northern Ireland and their views and experiences with regard to these choices. The key findings of the study are similar to the findings of national and international studies. ${ }^{2,11,13-15,17,19,20,23,24}$ The evidence clearly shows that, while the majority of patients feel fully informed and involved in the decision-making processes around treatment and management of their CKD, not all patients receive sufficient information to make an informed choice about their treatment and that treatment options are not always presented to patients and their families to enable them to make a fully informed choice.

It is recommended that:

- Tailored information be provided to patients to enable patients and their families to make informed choices within the context of their own circumstances;

- Information on all available treatment options, in particular home dialysis, be offered to patients and their families in a fully informed way to enable patients and their families to choose their preferred therapy;

- Further research be undertaken into the reasons why some patients do not feel involved in the decision-making process with regard to the treatment and management of their condition; and

- Further research be undertaken into what types of information patients feel would be useful to them in the context of CKD, lifestyle, and dialysis and the manner in which this should be provided. 


\section{Author contributions}

SK: conception of study, participated in design and coordination, and drafting of the manuscript. HM: conception of study, participated in design of study, and editing of the manuscript. Both authors approved the final manuscript.

\section{Disclosure}

Study was funded by Baxter Healthcare International. The authors report no conflicts of interest in this work.

\section{References}

1. Hollander S. Providing health information to the general public: a survey of current practices in academic health sciences libraries. Bulletin of the Medical Library Association. 2000;88(1):62-69..

2. Orsino A, Cameron JI, Seidl M, Mendelssohn D, Stewart DE. Medical decision-making and information needs in end-stage renal disease patients. Gen Hosp Psychiatry. 2003;25:324-331.

3. Andrews JE, Johnson JD, Case DO, Allard S, Kelly K. Intention to seek information on cancer genetics. Information Research. 2005; 10(4):238

4. Deber RB, Kraetschmer N, Urowitz S, Sharpe N. Do people want to be autonomous patients? Preferred roles in treatment decisionmaking in several patient populations. Health Expect. 2007;10: 248-258.

5. Taylor S, Field D. Sociology of Health and Health Care. 4th Edition. 2007; Oxford, England: Blackwell Publishing.

6. Johansson L. Shared decision making and patient involvement in choosing home therapies. J Ren Care. 2013;39 Suppl 1:9-15.

7. Wyatt JC. Information for patients. J R Soc Med. 2000;6(93): $467-471$.

8. Coulter A, Ellins J. Effectiveness of strategies for informing, educating and involving patients. Brit Med J. 2007;335:24-27.

9. Caress A, Luker K., Woodcock A, Beaver KA. Qualitative exploration of treatment decision making role preference in adult asthma patients. Health Expectations. 2002;5:233-235.

10. Levinson W, Kao A, Kuby A, Thisted RA. Not all Patients want to participate in decision making: A National Study of Public Preferences. J Gen Intern Med. 2005;20(6):531-535.

11. Murray MA, Brunier G, Chung JO, et al. A systematic review of factors influencing decision-making in adults living with chronic kidney disease. Patient Educ Couns. 2009;76:149-158.

12. Guidelines and Audit Implementation Network (GAIN). Northern Ireland Guidelines for Acute Kidney Injury. Belfast: GAIN, NI; 2010.

13. Tweed AE, Ceaser K. Renal replacement therapy choices for predialysis renal patients. Br J Nurs. 2005;14(12):659-664.

14. Morton RL, Tong A, Howard K, Snelling P, Webster AC. The views of patients and carers in treatment decision making for chronic kidney disease: systematic review and thematic synthesis of qualitative studies. BMJ. 2010;340:c112.

15. Chanouzas D, Ng KP, Fallouh B, Baharani J. What influences patient choice of treatment modality at the pre-dialysis stage? Nephrol Dial Transplant. 2012;27:1542-1547.
16. Covic A, Bammens B, Lobbedez T, et al. Educating end-stage renal disease patients on modality selection: a clinical advice from the European Renal Best Practice Advisory Board. Nephrol Dial Transplant. 2010;25(6):1757-1759.

17. European Kidney Patients' Federation (CEAPIR). Unequal Treatment for Kidney Patients in Europe: Patient Survey and Analysis of Renal Care Across The European Union. CEAPIR; 2012. Available from: http://www.nyreforeningen.dk/download/DagsordnerOgReferater/ Internationalt_udvalg/Ovrigt/ceapir_renal_care_report.pdf. Accessed September 9, 2014.

18. Szabo E, Moody H, Hamilton T, Ang C, Kovithavongs C, Kjellstrand C. Choice of treatment improves quality of life: a study on patients undergoing dialysis. Arch Intern Med. 1997;157(12):1352-1356.

19. Breckenridge DM. Patients' perceptions of why, how, and by whom dialysis treatment modality was chosen. ANNA J. 1997;24(3):313-319.

20. Wuerth DB, Finkelstein SH, Schwetz O, Carey H, Kliger AS, Finkelstein FO. Patients' descriptions of specific factors leading to modality selection of chronic peritoneal dialysis or hemodialysis. Perit Dial Int. 2002;22:184-190

21. Little J, Irwin A, Marshall T, Rayner H, Smith S. Predicting a patient's choice of dialysis modality: experience in a United Kingdom renal department. Am J Kidney Dis. 2001;37(5):981-986.

22. Stack AG. Determinants of modality selection among incident US dialysis patients: results from a national study. J Am Soc Nephrol. 2002; 13:1279-1287.

23. Lee A, Gudex C, Povlsen JV, Bonnevie B, Nielsen CP. Patients' views regarding choice of dialysis modality. Nephrol Dial Transplant. 2008; 23:3953-3959.

24. Harwood L, Clark AM. Understanding pre-dialysis modality decisionmaking: a meta-synthesis of qualitative studies. Int J Nurs Stud. 2013; 50:109-120.

25. Morton RL, Howard K, Webster AC, Snelling P. Patient INformation about Options for Treatment (PINOT): a prospective national study of information given to incident CKD Stage 5 patients. Nephrol Dial Transplant. 2011;26:1266-1274.

26. Morton RL, Snelling P, Webster AC, et al. Dialysis modality preference of patients with CKD and family caregivers: a discrete-choice study. Am J Kidney Dis. 2012;60(1):102-111.

27. Whittaker AA, Albee BJ. Factors influencing patient selection of dialysis modality. ANNA. 1996;23(4):369-375.

28. Miles MB, Huberman AM. Qualitative Data Analysis: An Expanded Sourcebook. New York: Sage; 1994.

29. Deber RB, Kraetschmer N, Urowitz S. Do people want to be autonomous patients? Preferred roles in treatment decision making in several patient populations. Health Expectations. 2007;10(3):248-258.

30. Charles C, Gafni A, Whelan T. Shared decision-making in the medical encounter: what does it mean? (or it takes at least two to tango). Soc Sci Med. 1997;44(5):681-692.

31. Charles C, Gafni A, Whelan T. Decision-making in the physician-patient encounter: revisiting the shared treatment decision-making model. Soc Sci Med. 1999:49;651-661.

32. Charles C, Whelan T, Gafni A. What do we mean by partnership in making decisions about treatment? BMJ. 1999;319:780-782.
Patient Preference and Adherence

\section{Publish your work in this journal}

Patient Preference and Adherence is an international, peer-reviewed, open access journal that focuses on the growing importance of patient preference and adherence throughout the therapeutic continuum. Patient satisfaction, acceptability, quality of life, compliance, persistence and their role in developing new therapeutic modalities and compounds to optimize

\section{Dovepress}

clinical outcomes for existing disease states are major areas of interest for the journal. This journal has been accepted for indexing on PubMed Central. The manuscript management system is completely online and includes a very quick and fair peer-review system, which is all easy to use. Visit http://www. dovepress.com/testimonials.php to read real quotes from published authors. 